\title{
Remarkable body weight gain in a patient in the terminal phase of gastric carcinoma secondary to 'big IGF-II'- producing tumor
}

\author{
Genta Ishikawa, Naoki Nishimura, Teruhiko Yoshida, Atsushi Kitamura, \\ Yasuhiko Yamano, Yutaka Tomishima, Torahiko Jinta, Koyu Suzuki, \\ Naohiko Chohnabayashi
}

\begin{abstract}
Introduction: Weight loss as a result of cachexia with malignancy is frequently encountered in clinical practice. However, previous reports have not demonstrated weight gain in terminal phase of malignancy. Case Report: We report a 69-year-old male admitted with an exacerbation of interstitial pneumonia and multiple metastases of relapsed gastric adenocarcinoma complicated with refractory hypoglycemia. He had gained approximately $10 \mathrm{~kg}$ weight with an acromegaloid appearance in a one-month period before admission. The presence of big insulin-like growth fact II (Big IGF-II) in his blood and an immunohistochemical study on the tumor cells confirmed a diagnosis of nonislet cell tumor hypoglycemia. Conclusion: This report possibly illustrates an unreported differential diagnosis of weight gain in terminal phase of malignancy.
\end{abstract}

Keywords: Gastric carcinoma, Non-islet cell tumor hypoglycemia (NICTH), Body weight gain

Genta Ishikawa ${ }^{1}$, Naoki Nishimura ${ }^{1}$, Teruhiko Yoshida ${ }^{1}$, Atsushi Kitamura ${ }^{1}$, Yasuhiko Yamano ${ }^{1}$, Yutaka Tomishima ${ }^{1}$, Torahiko Jinta ${ }^{1}$, Koyu Suzuki ${ }^{2}$, Naohiko Chohnabayashi ${ }^{2}$

Affiliations: ${ }^{1}$ Division of Pulmonary Medicine, St. Luke's International Hospital; 2Department of Pathology, St. Luke's International Hospital.

Corresponding Author: Genta Ishikawa, Division of Pulmonary Medicine, St. Luke's International Hospital, Akashi-cho 9-1, Chuo-ku, Tokyo, 104-8560, Japan; Tel: +81-3-3541-5151; Fax No: +81-3-3544-0649; E-mail: gentahot@hotmail.com

Received: 13 December 2013

Accepted: 11 May 2013

Published: 01 July 2013
Ishikawa G, Nishimura N, Yoshida T, Kitamura A, Yamano Y, Tomishima Y, Jinta T, Suzuki K, Chohnabayashi N. Remarkable body weight gain in a patient in the terminal phase of gastric carcinoma secondary to 'big IGF-II'- producing tumor. International Journal of Case Reports and Images 2013;4(7):380-383.

$* * * * * * * * *$

doi:10.5348/ijcri-2013-07-336-10

\section{INTRODUCTION}

Non-islet cell tumor hypoglycemia (NICTH) is a rare condition of malignancy. It has been considered as a cause of refractory hypoglycemia, which results from an abnormal secretion of big insulin growth factor-II (Big IGF-II) from tumor cells. This case report describes significant weight gain with an acromegaloid appearance in a 69-year-old male with NICTH associated with Big IGF-II producing tumor in the terminal phase of gastric adenocarcinoma.

\section{CASE REPORT}

A 69-year-old male with relapsed gastric adenocarcinoma (total gastrectomy and Roux-en-Y reconstruction were performed in September 2009) and systemic metastases was admitted to our hospital for severe respiratory failure as a result of an acute exacerbation of interstitial pneumonia on June 22, 2011. He had gained approximately $10 \mathrm{~kg}$ weight with acromegaloid features in a one-month period before his admission (Figures 1 and 2). He had noticed his shoes were too small for his feet and his wedding ring no longer fit in his finger. 
On the day of admission, he suffered from severe hypoglycemia (blood sugar $28 \mathrm{mg} / \mathrm{dL}$ ). He had an acromegaloid appearance with enlargement of hands, prognathism, and increased heel pad thickness without edema in his extremities (Figure 1). Skin tags, excessive oiliness of the skin and rhinophyma were also observed. He was given $10 \%$ dextrose intravenously and $1 \mathrm{mg}$ intramuscular glucagon. In addition, methylprednisone $1 \mathrm{~g} /$ day was commenced for the exacerbation of interstitial pneumonia. Despite these therapies, his hypoglycemia persisted and 10\% dextrose infusion continued to be necessary to maintain the glucose level until his death.

The laboratory examination showed no increased levels of insulin (4.0 $\mu \mathrm{U} / \mathrm{mL}$, normal limit 1.7-10.4 $\mu \mathrm{U} / \mathrm{mL}$ ), growth hormone $(1.786 \mathrm{ng} / \mathrm{mL}$, normal limit $<5.0 \mathrm{ng} / \mathrm{mL}$ ) and insulin growth factor-I (IGF-I, 41.8 $\mathrm{ng} / \mathrm{mL}$, normal limit 42-250 ng/mL). Furthermore, Cpeptide level in the urine sample was suppressed ( 0.3 $\mu \mathrm{g} /$ day, normal limit 20.1-155.0 $\mu \mathrm{g} /$ day). Western blot analysis of IGF-II in sera obtained at hypoglycemia disclosed a two-fold higher molecular IGF-II (Big IGFII) when compared with normal human IGF-II (7.5 $\mathrm{kDa}$ ) (Figure 3). The computed tomography (CT) scan showed diffuse ground glass opacities with traction bronchiectasis throughout the lungs as well as multiple lung metastases with bilateral pleural effusion and mediastinal lymphadenopathy and the metastasis had markedly increased in extent compared to the CT scan performed two months before admission (Figure 4). Echocardiography demonstrated normal left ventricular
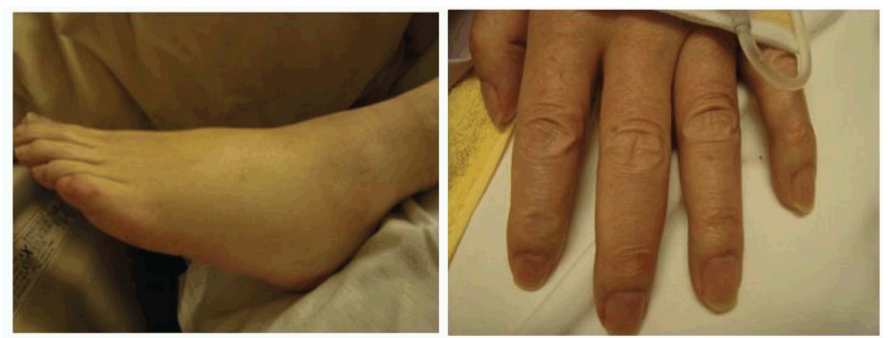

Figure 1: Enlargement of left hand and increased heel pad thickness.

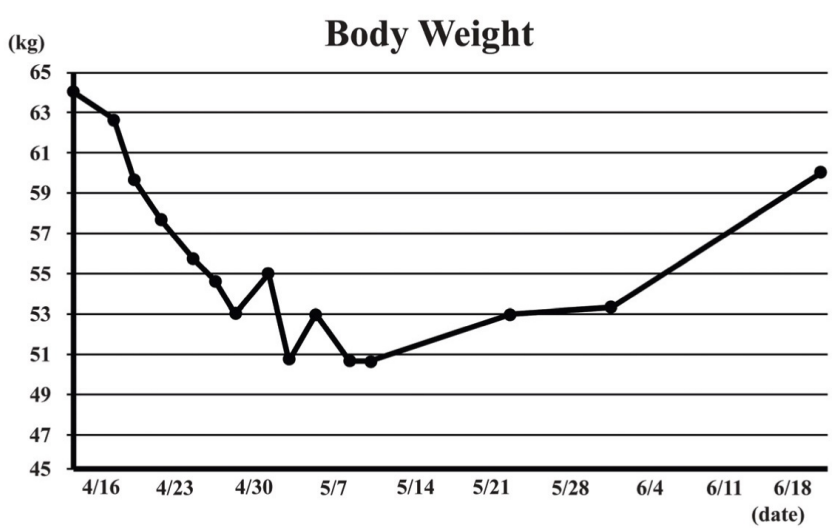

Figure 2: Body weight change in the clinical course. contraction, and serum NT-pro-BNP level was 383.4 $\mathrm{pg} / \mathrm{mL}$, (normal limit <125.0 pg/mL). Massive proteinuria and severe liver dysfunction had not been observed. An increased thickness of abdominal subcutaneous tissue was detected in CT scan (Figure 4). The patient died three days after admission due to uncorrectable respiratory failure induced by interstitial pneumonia.

The postmortem examination confirmed a diagnosis of poorly differentiated gastric adenocarcinoma with metastases to lungs, thyroid, pancreas and lymph nodes. Diffuse alveolar damage and chronic interstitial pneumonia were also recognized. Immunohistochemical study using polyclonal anti-IGF-

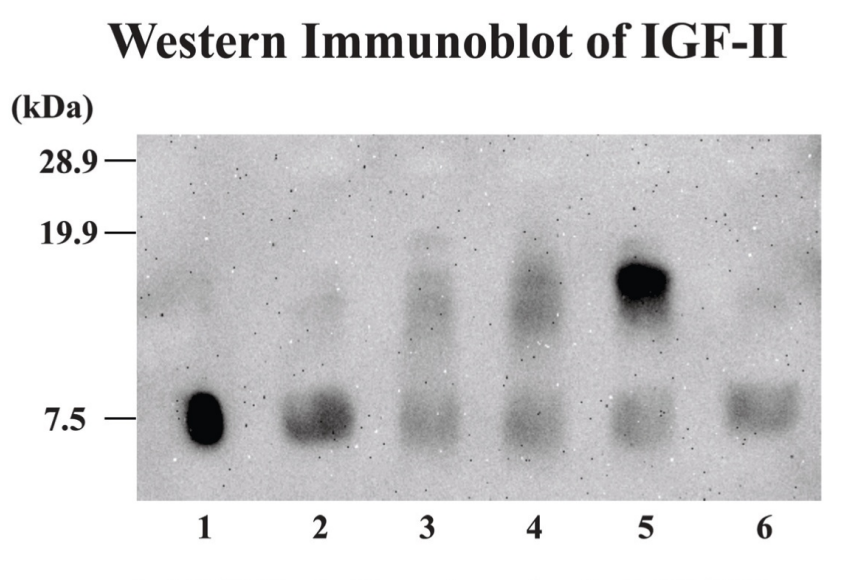

1: hIGF-II, 2: Hypoglycemia, 3, 5: NICTH, 4: Patient, 6: Normal

Figure 3: Western Blot in serum analysis of IGF-II in sera. A two-fold higher molecular IGF-II (Big IGF-II) compared with the control, IGF-II: insulin-like growth factor-II.
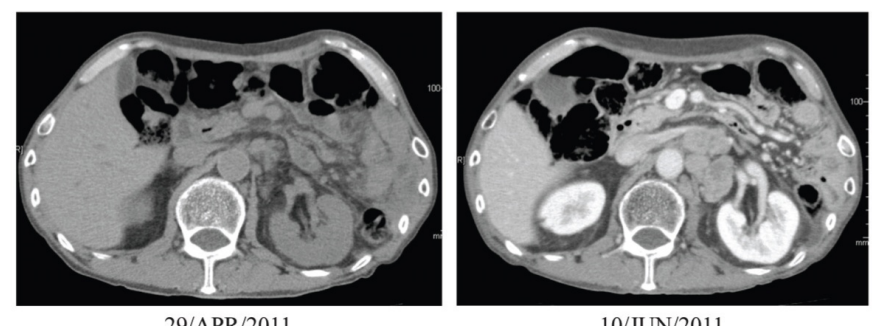

29/APR/2011

10/JUN/2011
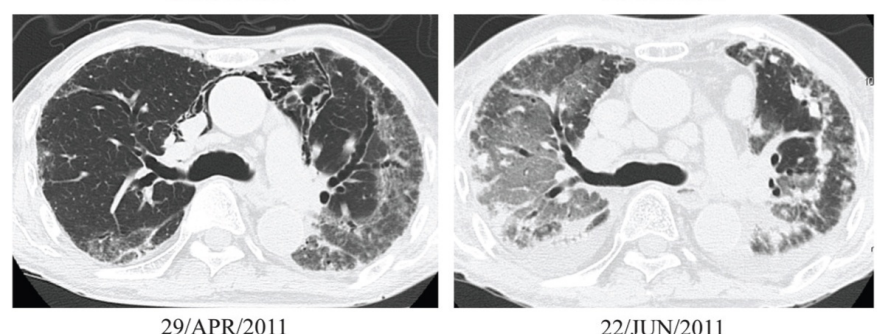

Figure 4: The computed tomography scan showing diffuse ground glass opacities with traction bronchiectasis throughout the lungs, as well as multiple lung metastases with bilateral pleural effusion and mediastinal lymphadenopathy (right), and the metastasis had markedly increased in extent compared to the computed tomography performed two months before admission (left). 
II antibody (ab9574; Abcam, Cambridge, UK) demonstrated a positive staining of IGF-II in tumor cells (Figure 5). Additionally, the immunohistochemistry with anti-IGF-II demonstrated a positive staining in the specimen of primary gastric cancer resected in 2009. Taking into account the detection of Big IGF-II in his blood, the result of immunohistochemistry and refractory hypoglycemia, we made a final diagnosis of NICTH.

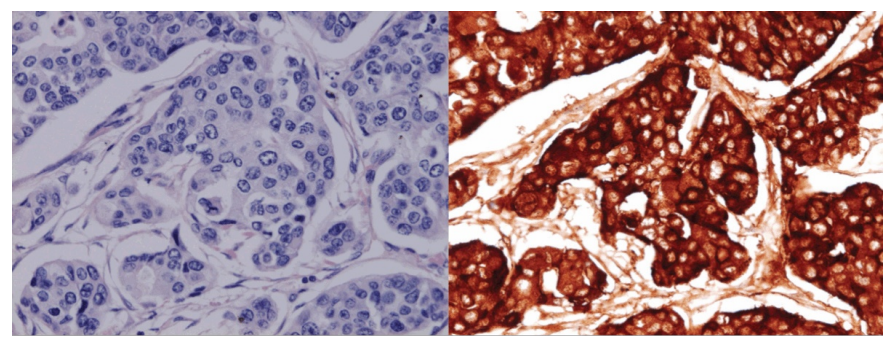

Figure 5: Immunohistochemical study using polyclonal antiIGF-II antibody demonstrating a positive staining of IGF-II in tumor cells, IGF-II: insulin-like growth factor-II.

\section{DISCUSSION}

The NICTH is a rare condition and was first reported in 1929 with hepatocellular carcinoma. In 1988, the relationship between the aberrant production of proIGF-II (Big-IGF-II) and tumor-induced hypoglycemia was first proposed. Several case reports of tumorinduced hypoglycemia have been published and various tumors can result in NICTH. Data on the exact incidence and prevalence of NICTH are not available. However, it usually occurs in a subject with solid tumors of welldifferentiated mesenchymal origin [1-3]. Also, gastric carcinoma is one of the most possible causes of NICTH [4], and several case reports have been published [5].

While the synthesis of IGF-I in liver is largely regulated by growth hormone (GH), the synthesis of IGF-II is independent of GH action. IGF-II originally has a role in fetal development, cell proliferation and apoptosis $[6,7]$. Both IGF-I and IGF-II are structurally and functionally associated with insulin. Big IGF-II is an immature form of IGF-II, whose bioavailability is markedly increased because of its tendency to cross the capillary barrier and activate the insulin receptors more easily than mature IGF-II [8]. In NICTH patients, the tumor cells overexpress the IGF-II gene and the abnormal IGF-II produced by the tumor causes refractory hypoglycemia by direct interaction with insulin receptors $[9,10]$. In addition, IGF-II is a potent mitogen for many cell types in the autocrine, paracrine and endocrine fashions, which possibly indicates that overproduction of Big-IGF-II from residual tumor cells may facilitate tumor growth (anabolic activity).

Acromegaloid skin changes, such as skin tags, excessive oiliness of the skin and rhinophyma, have been reported in patients with NICTH $[11,12]$. This patient demonstrated the acromegaloid features.

Furthermore, this report showed a remarkable finding of weight change during the clinical course. At first, he lost about $10 \mathrm{~kg}$ in one month, followed by a gain of approximately $10 \mathrm{~kg}$ in the one month before his death (Figure 2). In radiographic investigation (CT scan), thickened subcutaneous tissue compared to the image taken two months before was observed. We suppose at first the initial body weight loss resulted from cachexia state surpassing anabolic activity with Big IGF-II production. Furhter, we suppose anabolic activity of Big IGF-II towards not only tumor cells but also normal cells possibly accounted for the remarkable weight gain. We ruled out the existence of insulinoma and primary acromegaly with laboratory data. Worsening fluid accumulation was excluded by the physical examinations, unchanged BNP level in his blood and normal ventricular contraction on echocardiography. Obesity was not probable because his diet had not changed during the clinical course.

The limitation of our report was we could not investigate thyroid function that could influence weight change. Further, we could not demonstrate histological finding of anabolic state in subcutaneous tissue.

\section{CONCLUSION}

This is the first report demonstrating weight gain in the terminal phase of malignancy. The possibility of Non-islet cell tumor hypoglycemia might be investigated when encountering malignancy with remarkable weight gain.

\section{Acknowledgements}

We thank Izumi Fukuda (Department of Medicine, Institute of Clinical Endocrinology Tokyo Women's Medical University) for processing the western blot analysis, and Eri Ishikawa, Miyako Uetake for processing the immunohistochemical study.

$* * * * * * * * *$

\section{Author Contributions}

Genta Ishikawa - Conception and design, Acquisition of data, Analysis and Interpretation of data, Drafting the article, Revising it critically for important intellectual content, Final approval of the version to be published Naoki Nishimura - Conception and design, Acquisition of data, Analysis and Interpretation of data, Drafting the article, Revising it critically for important intellectual content, Final approval of the version to be published

Teruhiko Yoshida - Conception and design, Acquisition of data, Analysis and Interpretation of data, Drafting the article, Revising it critically for important intellectual content, Final approval of the version to be published

Atsushi Kitamura - Conception and design, Acquisition of data, Revising it critically for important intellectual content, Final approval of the version to be published 
Yasuhiko Yamano - Conception and design, Acquisition of data, Revising it critically for important intellectual content, Final approval of the version to be published Yutaka Tomishima - Conception and design, Acquisition of data, Revising it critically for important intellectual content, Final approval of the version to be published

Torahiko Jinta - Conception and design, Acquisition of data, Revising it critically for important intellectual content, Final approval of the version to be published Koyu Suzuki- Conception and design, Acquisition of data, Revising it critically for important intellectual content, Final approval of the version to be published Naohiko Chohnabayashi - Conception and design, Acquisition of data, Revising it critically for important intellectual content, Final approval of the version to be published

\section{Guarantor}

The corresponding author is the guarantor of submission.

\section{Conflict of Interest}

Authors declare no conflict of interest.

\section{Copyright}

(C) Genta Ishikawa et al. 2013; This article is distributed under the terms of Creative Commons attribution 3.0 License which permits unrestricted use, distribution and reproduction in any means provided the original authors and original publisher are properly credited. (Please see www.ijcasereportsandimages.com /copyright-policy.php for more information.)

\section{REFERENCES}

1. de Groot JW, Rikhof B, van Doorn J, et al. Non-islet cell tumour-induced hypoglycaemia: a review of the literature including two new cases. Endocr Relat Cancer 2007;14(4):979-93.
2. Nadler WH, Wolfer JA. Hepatogenic hypoglycemia associated with primary liver cell carcinoma. Arch Intern Med 1929;44:700-5.

3. Hizuka N, Fukuda I, Takano K, Okubo Y, AsakawaYasumoto K, Demura H. Serum insulin-like growth factor II in 44 patients with non-islet cell tumor hypoglycemia. Endocr J 1998:45(Suppl):S61-5.

4. Fukuda I, Hizuka N, Ishikawa Y, et al. Clinical features of insulin-like growth factor-II producing non-islet-cell tumor hypoglycemia. Growth Horm IGF Res 2006 Aug;16(4):211-6.

5. Kato A, Bando E, Shinozaki S, et al. Severe Hypoglycemia and Hypokalemia in Association with Liver Metastases of Gastric Cancer. Intern Med 2004;43(9):824-8.

6. Jones JI, Clemmons DR. Insulin-like growth factors and their binding proteins: biological actions. Endocr Rev 1995;16(1):3-34.

7. van der Ven LT, Van Buul-Offers SC, Gloudemans T, et al. Modulation of insulin-like growth factor (IGF) action by IGF-binding proteins in normal, benign, and malignant smooth muscle tissues. J Clin Endocrinol Metab 1996;81(10):3629-35.

8. Zapf J. Role of insulin-like growth factor II and IGF binding proteins in extrapancreatic tumor hypoglycemia. Horm Res 1994;42(1-2):20-6.

9. Zapf J, Futo E, Peter M, Froesch ER. Can "big" insulin-like growth factor II in serum of tumor patients account for the development of extrapancreatic tumor hypoglycemia? J Clin Invest 1992;90(6):2574-84.

10. Zapf J. Role of insulin-like growth factor II and IGF binding proteins in extrapancreatic tumor hypoglycemia. Horm Res 1994;42(1-2):20-6.

11. Trivedi N, Mithal A, Sharma AK, et al. Non-islet cell tumour induced hypoglycaemia with acromegaloid facial and acral swelling. Clin Endocrinol (Oxf) 1995;42(4):433-5.

12. Bertherat J, Logié A, Gicquel C, Mourriéras F, Luton JP, Le Bouc Y. Alterations of the 11p15 imprinted region and the IGFs system in a case of recurrent non-islet-cell tumour hypoglycaemia (NICTH). Clin Endocrinol (Oxf) 2000;53(2):213-20.
Access full text article on other devices

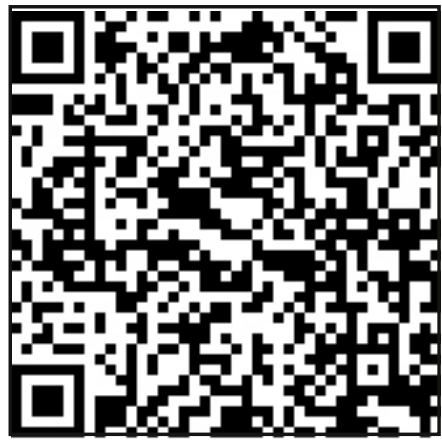

Access PDF of article on other devices

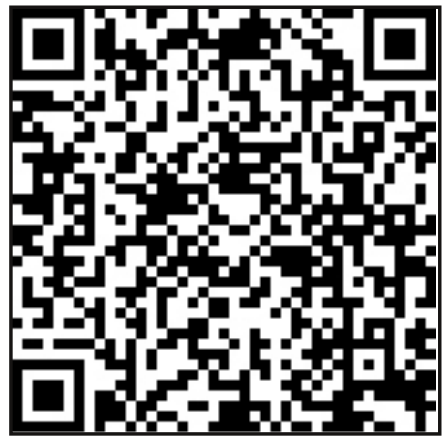

